\title{
Urban living walls: reporting on maintenance challenges from a review of European installations
}

\author{
Kanchane Gunawardena* and Koen Steemers \\ The Martin Centre for Architectural and Urban Studies, Department of Architecture, University of Cambridge, \\ 1-5 Scroope Terrace, Cambridge, CB2 1PX, United Kingdom. \\ * Corresponding author: krag2@cam.ac.uk \\ Doi: https://doi.org/10.1080/00038628.2020.1738209
}

\begin{abstract}
In response to the need to mitigate urban heat risks, green infrastructure enhancements have been widely advocated in recent times. To meet the challenges of implementing enhancements in dense cities, surface greening approaches such as vertical living walls have gained increased prominence. This paper reports on the principal challenges and drivers influencing the sustainable maintenance of such installations, identified through the inspection of ten European case studies and interviews with their management authorities. The study reports on key maintenance areas highlighted by installation managers as requiring attention. Furthermore, it reports on human engagement behavioural aspects as being a significant motivator, with installation managers assigning value to building occupant and public perception of an installation's flourishing state. The evidence reported therefore is beneficial to key decisionmakers and designers when considering the inclusion and sustainable maintenance of such greening installations.
\end{abstract}

Keywords: green infrastructure; living walls; living wall maintenance; living wall case studies; plant stress management; sustainability of living walls

\section{Introduction}

Green infrastructure enhancements are widely advocated to address urban climate risks such as increasing temperatures and pollution. In cities with dense morphologies and reduced open spaces, surface greening has received increased attention as means to resourcefully achieve such enhancements (Gunawardena et al. 2017; Gunawardena \& Kershaw 2016). Although initial efforts promoted horizontal greening, vertical greening has gained significant favour given the recent advancements in application methods. Industry experts and suppliers in the UK for example report an upward trend in commissions (Grant 2017; Ward 2018a), while the research body considering various ecosystem benefits is similarly expanding (Gunawardena \& Steemers 2019b). Notwithstanding this growth trend, negative criticism associated with maintenance persists as a barrier for wider uptake (Perini et al. 2013; Perini \& Rosasco 2013). 
The two principal approaches of vertical greening are 'green facades' and 'living walls'; differentiated by the placing of the growth substrate (Fig. 1). While green facades are a wellestablished form of vertical greening, recent interest is directed at living walls (Gunawardena \& Steemers 2019b). The growth substrate in these is placed on the vertical host building wall, where plants root into a substrate carrying support-work that includes closed-loop irrigation and fertigation networks. The construction methods used further differentiates these as either continuous or modular. Continuous systems use a decoupled support-skin into which plants are individually plugged on-site, while modular systems use interlocking units that are typically pre-planted and transported ready for assembly. The substrates used in both systems vary with options including hydroculture felt, clay balls, peat chunks, peat moss, mineral wool, coconut fibres, or graded soils. The greater prominence of living walls is influenced by their aesthetic appeal, which has encouraged certain urban communities to assign greater value to such approaches (Collins et al. 2017). Encouraged by this demand, recent installations have been introduced to a diverse range of building typologies, scales, and outdoor and indoor conditions (Grant 2017; Ward 2018b). This paper reports on the principal challenges and drivers influencing the sustainable maintenance of such installations, identified through the inspection of ten European case studies and interviews with their management authorities.

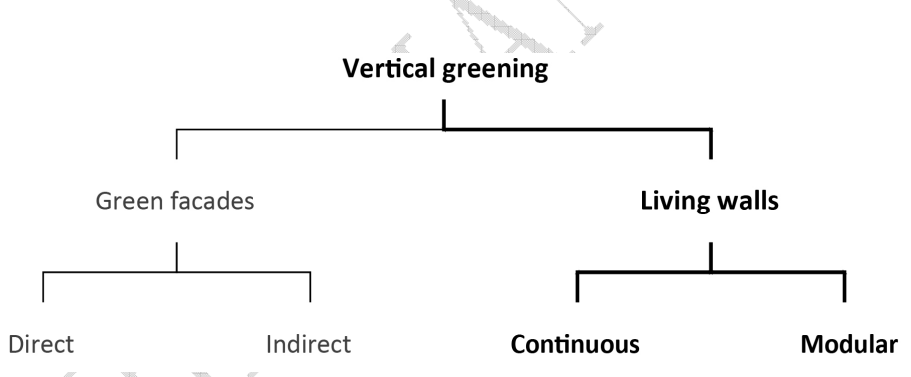

Fig. 1. Vertical greening typologies and focus.

\section{Methodology}

This study involved structured case study site inspections and associated unstructured interviews (see Bryman 2016). The site visits were carried out over the period between 2017-18 at ten installations located in the European cities detailed in Table 1. These were selected for representing significant coverage areas $\left(>30 \mathrm{~m}^{2}\right)$ in outdoor (8) and indoor (2) conditions; as well as for offering accessibility to carryout observational studies and conduct interviews with maintenance authorities. Save for one installation from the Mediterranean Köppen (Csa) climate zone, the rest are all located in maritime temperate $(\mathrm{Cfb})$ climates, where previous research had highlighted observational data to be limited (Gunawardena \& Steemers 2019b). All projects inspected have been anonymised in this paper to descriptions detailed in Table 1 and Fig. 2 to comply with management authority wishes. 
Table 1. The ten urban living wall case studies inspected.

\begin{tabular}{|c|c|c|c|c|c|}
\hline $\begin{array}{l}\text { Case } \\
\text { study }\end{array}$ & $\begin{array}{c}\text { Installed } \\
\text { (remove } \\
\text { d) } \\
\end{array}$ & $\begin{array}{l}\text { Location } \\
\text { (Köppen } \\
\text { climate) }\end{array}$ & $\begin{array}{l}\text { Host building } \\
\text { function }\end{array}$ & Instllation description & $\begin{array}{l}\text { System } \\
\text { description }\end{array}$ \\
\hline Project-A & $\begin{array}{c}2014 \\
(2015)\end{array}$ & $\begin{array}{l}\text { Cambridge, } \\
\text { England (Cfb) }\end{array}$ & $\begin{array}{l}\text { Communications } \\
\text { infrastructure }\end{array}$ & Exterior façade (corner), at remote site & $\begin{array}{l}\text { Mineralwool modular } \\
\text { plate-based }\end{array}$ \\
\hline Project-B & 2015 & Cambridge & $\begin{array}{r}\text { Multi-organisation } \\
\text { research campus }\end{array}$ & $\begin{array}{l}\text { Interior wall, in atrium }(\sim 15 \text { m-high }) \\
\text { void }\end{array}$ & Soil-based modular \\
\hline Project-C & 2017 & $\begin{array}{l}\text { London, England } \\
(\mathrm{Cfb})\end{array}$ & Private residence & $\begin{array}{l}\text { Exterior courtyard (walls installed on } \\
\text { three sides of a rear garden court) }\end{array}$ & $\begin{array}{l}\text { Soil-based modular- } \\
\text { pocket }\end{array}$ \\
\hline Project-D & 2013 & London & Hotel & Exterior façade (gable-end wall) & Soil-based modular \\
\hline Project-E & 2009 & London & Hotel & $\begin{array}{l}\text { Exterior façade (corner and high } \\
\text { elevation), fronting a busy stree }\end{array}$ & $\begin{array}{l}\text { Mur Vegetal (MV); } \\
\text { continuous felt- } \\
\text { based hydroponic }\end{array}$ \\
\hline Project-F & 2008 & $\begin{array}{l}\text { Madrid, Spain } \\
\text { (Csa) }\end{array}$ & Museum & Exterior façade (fronting a pub & MV \\
\hline Project-G & 2013 & $\begin{array}{l}\text { Paris, France } \\
(\mathrm{Cfb})\end{array}$ & $\begin{array}{l}\text { Residential flats } \\
\text { and retail }\end{array}$ & $\begin{array}{l}\text { Exterior gable-end façade (fronting a } \\
\text { small public court) }\end{array}$ & MV \\
\hline Project-H & 2004 & Paris & Museum & $\begin{array}{l}\text { Exterior façade (fronting a wide } \\
\text { boulevard) }\end{array}$ & MV \\
\hline Project-I & 2008 & $\begin{array}{l}\text { Toulouse, France } \\
(\mathrm{Cfb})\end{array}$ & Museum & $\begin{array}{l}\text { Interior wall, in atrium ( 16 m-high) } \\
\text { void }\end{array}$ & MV \\
\hline Project-J & $2008^{*}$ & Toulouse & Botanic garden & $\begin{array}{l}\text { Interior wall, in greenhouse with base } \\
\text { pond }\end{array}$ & MV \\
\hline
\end{tabular}

* Original installation from 1996 dismantled for major renovation.

Mur Vegetal (MV)

\begin{tabular}{|c|c|c|c|c|}
\hline \multirow{3}{*}{$\begin{array}{l}\text { - Species count } \\
\text { Plant density (plants per m²) }\end{array}$} & $\begin{array}{l}30 \\
\text { No data }\end{array}$ & Project-I & $\begin{array}{c}31(\mathrm{H} \sim 11 \mathrm{~m}) \\
930\end{array}$ & \multirow{3}{*}{$\begin{array}{r}\text { Plant count } \\
\text { Living wall area }\left(\mathrm{m}^{2}\right) \\
\mathrm{H} \text { : Living wall height }(\mathrm{m})\end{array}$} \\
\hline & $\begin{array}{c}10 \\
\text { No data }\end{array}$ & Project-J & $\begin{array}{l}75(\mathrm{H} \sim 7.5 \mathrm{~m}) \\
750\end{array}$ & \\
\hline & 31 & Project-H & $730(\mathrm{H} \sim 12 \mathrm{~m})$ & \\
\hline \multirow{3}{*}{376} & 47 & Project-E & | 256 (H 30 m) & 000 \\
\hline & 33 & Project-F & 460 (H 24 m) & 15000 \\
\hline & $30 \square$ & Project-G & | 250 (H 25 m) & \\
\hline
\end{tabular}

Soil-based

$\begin{array}{lll}96 & \text { Project-B } & \mid 91(\mathrm{H} \sim 13 \mathrm{~m}) \\ 24 & \text { Project-D } & 8740 \\ 22 & 350\left(\mathrm{H}^{\sim 21} \mathrm{~m}\right) & 10000 \\ 49 & \text { Project-C } & 102\left(\mathrm{H}^{\sim 6 \mathrm{~m})}{ }_{5000}\right.\end{array}$

Mineralwool-based

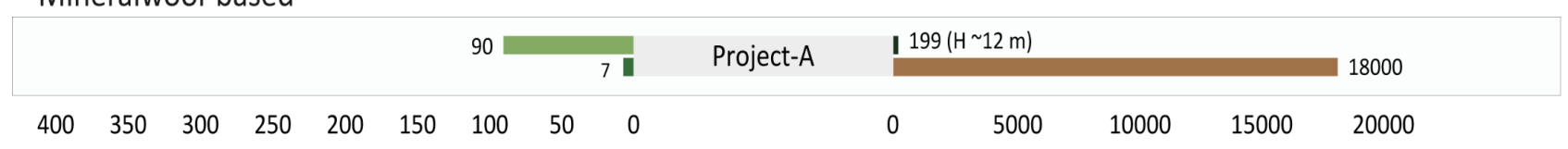

Fig. 2. Plant coverage properties of case studies. 
The site visits included two principal objectives. The first involved structured installation inspections (SI) carried out by a single inspector. They included the identification of plant and system failures (flourishing state indicator), biodiversity presence (healthy ecosystem), and evidence of resource oversupply (resource management). The non-structured observations also gathered during these visits included examples of watering, replacement planting, and horticultural practises (Appendix Table A1). The second objective involved structured non-participant observations of human engagement behavioural practises recorded by a single rater, at each site visit typically lasting for an hour. The engagement observation schedule recorded incidents or instances distinguished per visit between building occupant and visitor instances, as well as the type of engagement between those taking visual notice; making connections by means of conversation or taking photographs; active movement toward the feature; and physical contact and interaction with plants. The frequency of instances gathered in relation to this observational schedule (Table 3) was ordinally categorised based on frequencies representing 'none' (0), 'Very low' $(<2)$, 'Low' $(\geq 2$ and $<5)$, 'Moderate' $(\geq 5$ and $<7)$, 'High' ( $\geq 7$ and $<9)$, and 'Very high' $(\geq 9)$.

The above site visit data was complemented by unstructured interviews with expert practitioners/installation managers or key decisionmakers associated with the installations inspected. The installation managers were all answerable to the end-occupiers of the buildings concerned, except for the failed Project-A where the key decisionmaker was responsible for project procurement. The unstructured topics discussed included installation and service-life incidents; failures of plants and systems; maintenance programmes and their operation; resource consumption (water and nutrients); maintenance costs; as well as the influence of human engagement aspects. The response notes were processed using Matlab R2019b, Text Analytics Toolbox (MathWorks, Natick, MA, USA), and coded to eight maintenance-related subtopics and one concerning engagement behaviour.

Only the unstructured interviews in this study involved contact with human participants (interview subjects), which followed requisite ethical guidance. Material from these have been anonymised to comply with interviewee wishes, while certain sources in relation to projects are intentionally not referenced to comply with the confidential nature of such material.

\section{Findings}

\subsection{Maintenance observations}

A summary of key incidents reported in interviews and during the inspection campaign are detailed in Appendix Table A1, while the key themes of concern coded in the interviews are discussed in section 4 under eight maintenance-related subtopics. 
From the structured observations recorded at inspections, installations were nominally categorised as either 'flourishing' or 'failed' predicated on the estimated percentage of plant failures. Any installation with over 30\% (upper limit for expected failures, Ward 2018a) was deemed a failed state, with only Project-A designated as such given the entire installation having been removed. The failure rates for the remaining installations were relatively stable over the inspection campaign, all within $5-10 \%$ of expected failures (Table 2). The flourishing state was further qualified by the biodiversity presence recorded (healthy ecosystem indicator). This nominal categorisation required invertebrate and/or vertebrate presence, with most inspections (90\%) demonstrating visible invertebrate presence (e.g. insects), while a few outdoor installations also included vertebrate presence (8\%, e.g. bird-nesting). There was however a marked difference between indoor and outdoor installations, with the latter presenting greater presence of visually apparent diversity (largely characterised by invertebrates). The final structured observation identified resource oversupply. All MV systems in this regard showed water supply dripping into their waste collection drains, while a few demonstrated significant overspray to surroundings (e.g. Project-E,-F, and -H; Fig. 6a). The non-structured observations also gathered during these visits including watering, replacement planting, and horticultural practises are discussed in section 4 .

Table 2. Nominal aspects recorded during site inspections.

\begin{tabular}{|c|c|c|c|c|c|c|c|c|}
\hline \multirow[t]{2}{*}{ Case study } & \multicolumn{2}{|c|}{ Design } & \multicolumn{6}{|c|}{ Structured installation inspections } \\
\hline & 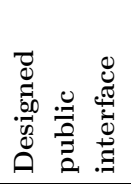 & 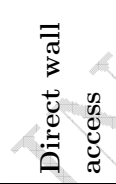 & 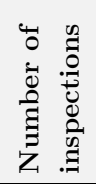 & 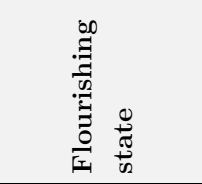 & 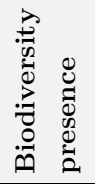 & 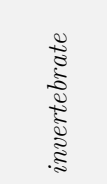 & 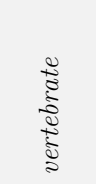 & 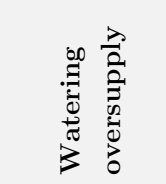 \\
\hline Project-A & No & No & 01 & No $(0 \%)$ & $\mathrm{N} / \mathrm{A}$ & $(\mathrm{N} / \mathrm{A})$ & $(\mathrm{N} / \mathrm{A})$ & $\mathrm{N} / \mathrm{A}^{*}$ \\
\hline Project-B & No & No & 08 & Yes $(\sim 90 \%)$ & Yes & $(6 / 8)$ & $(0 / 8)$ & No $(0 / 8)$ \\
\hline Project-C & & No & 04 & Yes $(\sim 85 \%)$ & Yes & $(4 / 4)$ & $(0 / 4)$ & No $(0 / 4)$ \\
\hline Project-D & & No & 03 & Yes $(\sim 95 \%)$ & Yes & $(2 / 3)$ & $(0 / 3)$ & No $(0 / 3)$ \\
\hline Project-E & & Yes & 02 & Yes $(\sim 90 \%)$ & Yes & $(2 / 2)$ & $(0 / 2)$ & Yes $(1 / 2)$ \\
\hline Project-F & & Yes & 20 & Yes $(\sim 95 \%)$ & Yes & $(20 / 20)$ & $(0 / 20)$ & Yes $(11 / 20)$ \\
\hline Project-G & Yes & No & 02 & Yes $(\sim 95 \%)$ & Yes & $(2 / 2)$ & $(1 / 2)$ & Yes $(1 / 2)$ \\
\hline Project-H & Yes & Yes & 08 & Yes † $(\sim 90 \%)$ & Yes & $(8 / 8)$ & $(3 / 8)$ & Yes (6/8) \\
\hline Project-I & Yes & Yes & 01 & Yes $(\sim 95 \%)$ & Yes & $(1 / 1)$ & $(1 / 1)$ & Yes $(1 / 1)$ \\
\hline Project-J & Yes & Yes & 01 & Yes $(\sim 95 \%)$ & No & $(0 / 1)$ & $(0 / 1)$ & Yes $(1 / 1)$ \\
\hline
\end{tabular}

$\dagger$ disregarding areas being replanted at the time of inspection; * historically recorded.

Save for Project-A, all other installations demonstrated only localised failures. These included species-specific ill-health or death; stress symptoms at installation edges; crown domination associated issues; and localised heat stress. With the Project-A failure, the trigger event had been identified as wintertime dry-out, which then led to other complications arising from remedial irrigation measures taken. The project however was climatically challenged from the 
onset when it was sited in a remote location with minimal surrounding shelter, followed by the application of the installation with considerable height to a building corner. The resultant wind-loading burden was therefore stressed in the post-failure assessment as a significant climate risk for the project. The lack of human engagement resulting from the building's use also meant that there had been little acknowledgment of the installation's ecosystem contributions, while stress symptoms and failures reported to the procurement team had been rapidly perceived and deemed as a defect of the installation, and to an extent the greening solution itself. This latter negative reaction is partly explained by the associated removal cost and replacement with an alternative, which was reported as a loss to the client of around $£ 1,500$ per $\mathrm{m}^{2}$.

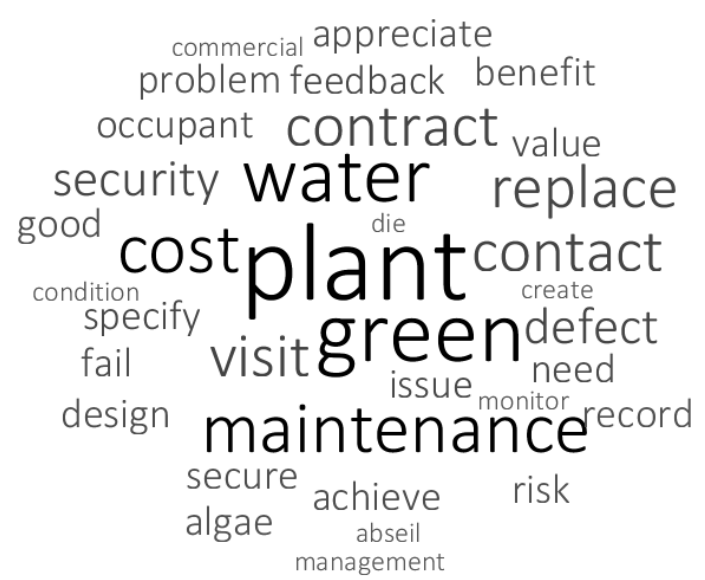

b

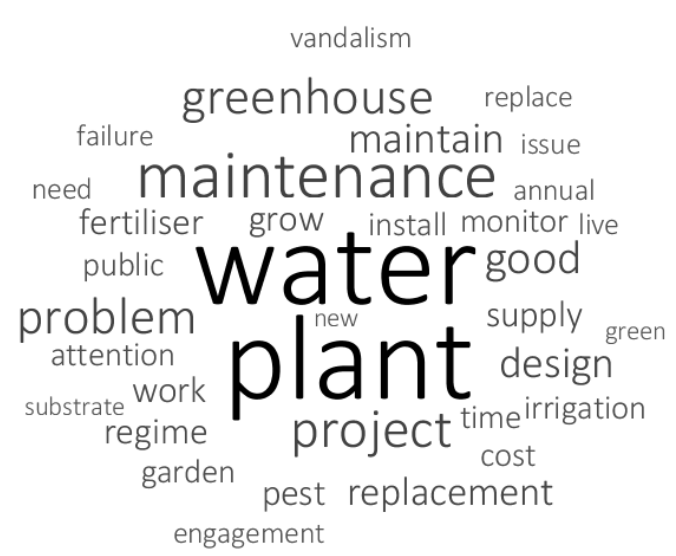

Fig. 3. Word-clouds from key decisionmaker (a) and expert consultant (b) interview response notes.

As demonstrated by interview response word-clouds (Fig. 3), concern for cost was stressed greater by key decisionmakers relative to expert consultants. Installation cost represented the primary concern given its proportional relevance to maintenance pricing; which varies with the system used. Mineral wool-based installation costs were estimated between $£ 375$ and $£ 425$ per $\mathrm{m}^{2}$ by a Madrid-based supplier, with $£ 550$ quoted by a UK-based supplier for a similar system. A soil-based modular felt-pocket system had comparable cost of $£ 500$ per $\mathrm{m}^{2}$ (UK-based), while MV systems presented the highest estimation exceeding $£ 600$ per $\mathrm{m}^{2}$ (Madrid-based). The secondary concern was the annual maintenance cost, which was quoted as a percentage of the installation cost ranging between 6\% (£29 per $\mathrm{m}^{2}$ at Project-C) and $12.5 \%$ (£62 per $\mathrm{m}^{2}$ at Project-B), while for MV installations it could be high as $15-20 \%$ (Madridbased). This varies depending on the nature of services included. A UK supplier for example quoted per plant replacement costs of $£ 3.00$ for outdoor and $£ 4.50$ for indoor installations, although this is said to be included for expected failures in most maintenance contracts. Complete substrate replacement and/or replanting however is a significant burden. With the above Mineral wool-based $£ 550$ per $\mathrm{m}^{2}$ system as an example, substrate replacement would cost $22.5 \%$ of installation, with complete replanting costing a further $45 \%$. 


\subsection{Flourishing state and human engagement behaviour}

The gathered frequency data on the six human engagement behavioural aspects (Fig. 4) were ordinally ranked by the earlier defined frequency thresholds (Table 3). Five of the flourishing projects offered direct access to their living walls, while seven presented a designed public interface. Notably, three sites included circulation arrangements with enhanced building user and public accessibility; namely the outdoor installations at Projects-E, -F, and -H (Table 2). At all three, pedestrian level access to the installations facilitated physical contact with plants (no threat of plant injury or vandalism was recorded during inspections; nor were any reported), with the MV installations recording the highest frequencies and complete range of behavioural interactions rated (Fig. 4).

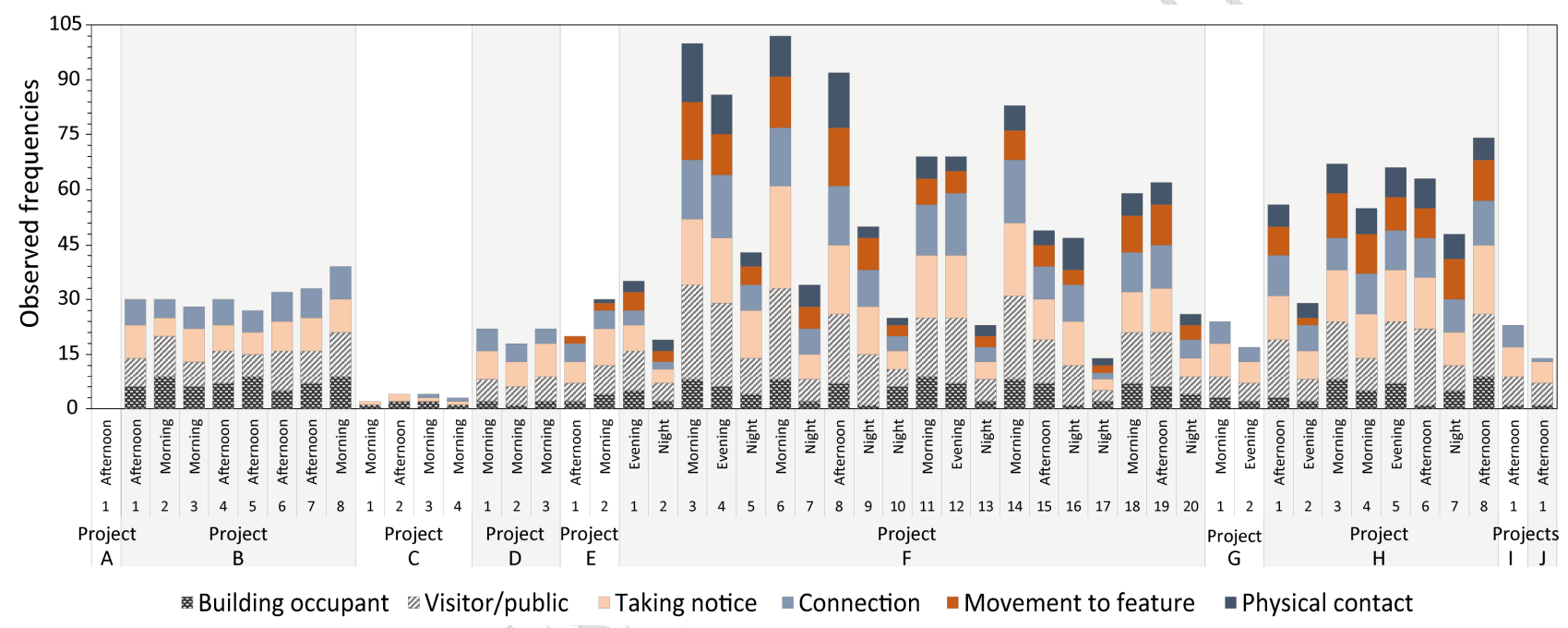

Fig. 4. Frequencies of human engagement aspects rated during site visits.

Table 3. Rated human engagement and interaction categories.

\begin{tabular}{|c|c|c|c|c|c|c|c|}
\hline $\begin{array}{l}\text { Percentage within } \\
\text { flourishing state }\end{array}$ & 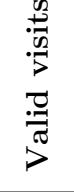 & 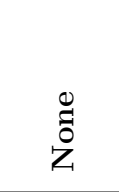 & $\begin{array}{l}3 \\
0 \\
\stackrel{3}{0} \\
>0 \\
>\end{array}$ & 茴 & 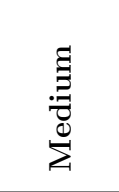 & 焉 & $\begin{array}{l}\frac{e}{00} \\
: 3 \\
\overrightarrow{0} \\
\overrightarrow{0}\end{array}$ \\
\hline Building occupant engagement & 49 & $0.0 \%$ & $16.3 \%$ & $32.7 \%$ & $18.4 \%$ & $22.4 \%$ & $10.2 \%$ \\
\hline Visitor/public engagement & 50 & $8.2 \%$ & $6.1 \%$ & $6.1 \%$ & $16.3 \%$ & $16.3 \%$ & $55.1 \%$ \\
\hline Taking notice & 49 & $0.0 \%$ & $6.1 \%$ & $6.1 \%$ & $16.3 \%$ & $16.3 \%$ & $55.1 \%$ \\
\hline Connection & 49 & $4.1 \%$ & $6.1 \%$ & $14.3 \%$ & $20.4 \%$ & $12.2 \%$ & $42.9 \%$ \\
\hline Movement toward feature & 39 & $23.1 \%$ & $0.0 \%$ & $23.1 \%$ & $10.3 \%$ & $10.3 \%$ & $33.3 \%$ \\
\hline Physical contact with plants & 36 & $19.4 \%$ & $2.8 \%$ & $27.8 \%$ & $16.7 \%$ & $16.7 \%$ & $16.7 \%$ \\
\hline
\end{tabular}


The overall engagement frequencies recorded during inspections highlighted 'visitor or public' engagement and the aspects relating to 'taking notice', 'making a connection', and 'movement toward the feature' to present the highest frequency in the 'Very high' category, while 'building occupant' engagement and the aspect of 'physical contact 'demonstrated the highest frequency in the 'Low' category. The overall lower engagement of building occupants could be partly explained by the sample studies underrepresenting indoor projects, where in isolation this was in the 'High' category.

The unstructured interview responses coded eight maintenance-related subtopics, while the value assigned to human engagement behaviours was extracted as a unique subtopic. The latter assignment was aligned closely with the agendas of the associated building function. For example, at museum installations (Projects-F, -H, and -I) they valued public perception mostly, while at Project-B with its multi-organisation building occupancy, both occupant and visitor perception was equally valued. At Project-A however the agenda contrasted, with the Planning Authority's acceptance of the 'concept of a flourishing installation' highlighted as the principal driver. The minimal occupancy and technical function of the building had also presented little engagement behaviours to influence the installation owner's value assignment.

\section{Discussion}

The installation managers highlighted plant stress management as the principal challenge in sustaining an urban installation's flourishing state (given the availability of adequate financial and other resources). While short-term demands within a species' tolerance limit are addressed by self-management mechanisms, atypical demand extremes present the risk of irrecoverable injury and rapid escalation to installation-level failure. Human management processes must therefore recognise stress symptoms as early as possible and intervene with appropriate measures, with the following stress management aspects highlighted by the respective experts as requiring significant attention.

\subsection{Managing local climate extremes}

Managing local climate loading is critical for the sustainable maintenance of urban living walls, with outdoor installations strongly influenced by local light, temperature, moisture, and wind climates. While plants are capable of acclimatising to reasonable extremes by dynamically adjusting their optimal, management experts must select plants with complementing climate hardiness ratings (e.g. David \& RHS 2013) to limit exposure risk. Atypical extremes however are a significant risk. For example, the principal contributing factors at Project-A's failure were identified as atypical lower winter temperatures and drought. Installation monitoring frequency during atypical extremes caused by heatwaves or cold snaps must therefore be increased to ensure rapid response to stress. In indoor conditions the climate is controlled to 
meet occupant comfort, which correspondingly satisfies optimal conditions for most plants. This limits thermal and water stress risk, although draughts from both hot (e.g. as experienced with heaters at Project-B) and cold sources have been reported to cause localised stress. Spaceconditioning objectives could also present complications as humidity is maintained at lower levels to ensure occupant comfort (relative humidity $\sim 40-70 \%$ ), which contradicts requirements for tropical shade-loving plants typically selected for such installations (85-95\%). The monitoring burden at indoor installations is as a result reported to be higher during the early establishing period, while afterward the climate variables are typically balanced by the managers to provide optimal growth conditions throughout the year (Ward 2018a).

The challenge of managing the light climate in cities is presented by contextual building overshadowing. Although this is addressed at the design stage and with the specification of shadeloving plants for surfaces in frequent shadow; the dynamic nature of urban renewal could result in unforeseen overshadowing risk. A few experts referred to past projects where this had been a major issue, although none of the installations inspected have thus far encountered such problems. Low-light availability in indoor installations on the other hand is a constant risk (Gunawardena \& Steemers 2019a; Ward 2018a). Although this is also addressed by specifying shade-loving plants, failures from low light availability is not uncommon even when tolerant species have been used (e.g. Orchidaceae failures at Project-J). The converse condition of high light exposure is an unlikely risk in indoor environments, although significant in outdoor conditions particularly with shade-loving plants. At Project-F for example, leaves of Hosta spp. exhibited irradiance stress symptoms, while tropical evergreens in general were reported to be frequently stressed from the higher irradiation loading at the south-facing installation. None of the installations inspected however seemed to employ real-time monitoring, with managers reporting light-level monitoring only as a task during regular site visits (Ward 2018a).

With low velocities wind flow is acknowledged to alleviate heat stress by enhancing heat and humidity advection, although at higher velocities increased humidity advection could encourage water stress, while directly causing wind-induced mechanical stress. Symptoms of wind stress are identified as thigmomorphogenesis features, which includes limited growth extents, canopy compaction, greater stem radial growth, and reduced number of leaves than typical. At several outdoor installations (e.g. Project-E), high-level plants demonstrated compact canopy arrangements to suggest prolonged exposure to wind stress. As these installations extend canopies to higher levels of exposure than otherwise typical (e.g. Project-E installation height is $>30 \mathrm{~m}$ ), edges and apexes are likely to be vulnerable to negative pressures resulting from turbulent flow (Monteith \& Unsworth 2013). This is likely to increase heat and mass transfer to increase the risk of drying, while in colder climates may also cause localised cold stress (e.g. as experienced at Project-A). If such conditions cannot be avoided by design, plant selection with high hardiness ratings mitigates the risk to an extent. 
Most local climate risks discussed above could be managed by using active thermal, humidity, or lighting controls to facilitate constant growth conditions. The feasibility to do so is greater with indoor conditions relative to outdoors, given the near closed nature of such systems. In any scenario however, the increased energy demand necessary to implement such active measures are likely to counter the beneficial ecosystem services and passive climate modifications expected. This in turn would call into question the sustainability of maintaining such installations.

\subsection{Irrigation}

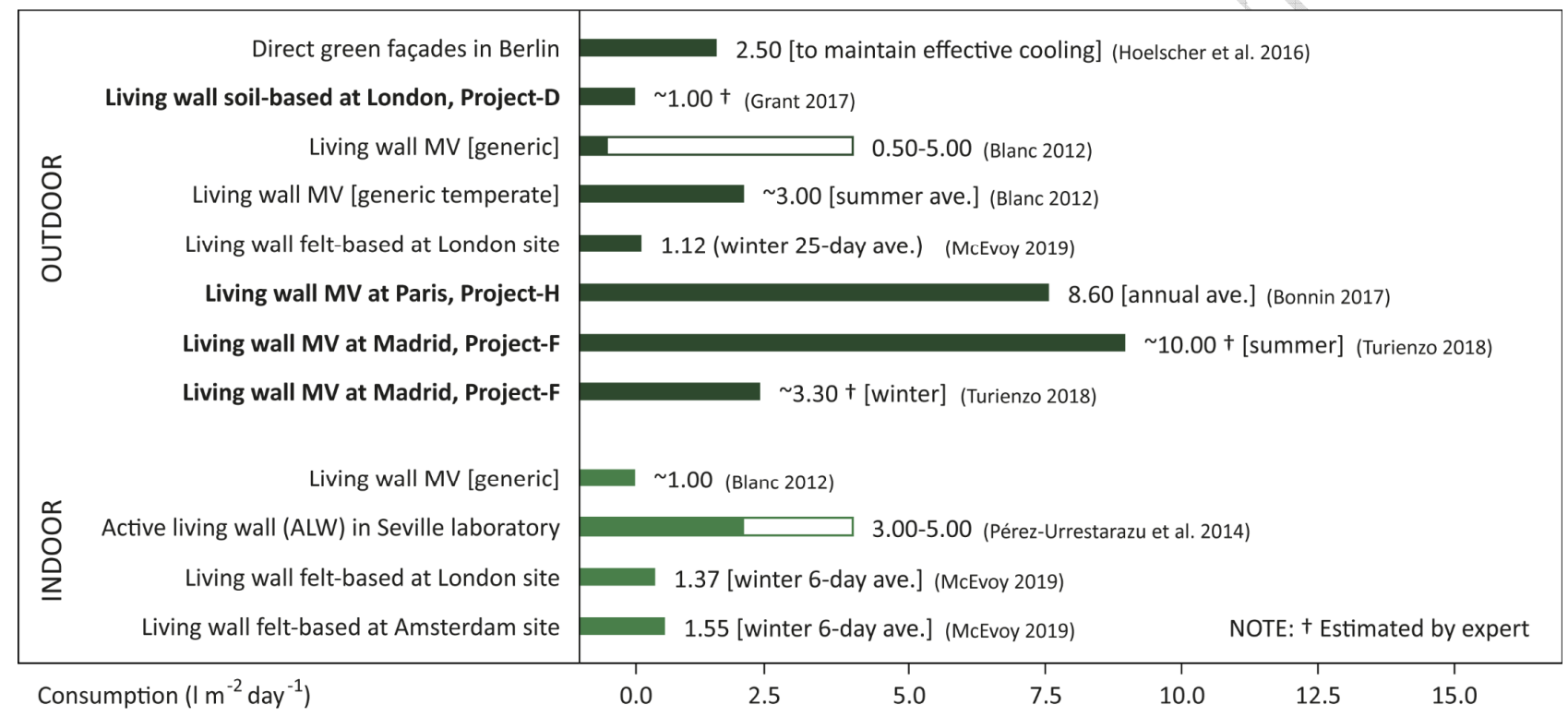

Fig. 5. Water consumption estimated or reported for indoor and outdoor installations.

Irrigation manages plant water demand and for living walls is dependent on the background climate, exposure, season, species, installation height, and system. With felt-based hydroponic systems, a relatively higher watering frequency is estimated to maintain a saturated substrate. The MV designer for example has recommended frequencies between 3-5 times a day (Blanc 2012). Soil-based systems in contrast have greater water retention capacity that translates to reduced frequencies (Grant 2017); as exemplified by the 1-2 frequency reported at Project-D. Programmes are also adjusted for seasonality with the growth season in spring and summer requiring higher frequency and volume (e.g. 3:1 summer-to-winter frequency split at ProjectF; and 3:2 at Project-J). Wintertime frequency is therefore lower, and in colder conditions restricted to mitigate frost damage (Turienzo 2018; Ward 2018a).

Water-use varies with system and consumption data is not widely reported (examples in Fig. 5). In sheltered indoor applications, consumption is reported to be relatively lower given the controlled climate. Some specialist indoor walls however require higher use as the plants used 
(bryophytes) require a saturated environment to thrive (e.g. ALW in Fig. 5). In outdoor conditions, consumption is greater given the exposure to the drying power of the atmosphere. Blanc (2012) had claimed MV supply burdens to be lower than typical for gardens and urban parks, although reported values at Project-H for example are higher than those for other systems. MV rates in drier climates like at Project-F is more pronounced, particularly in summer months. Water demands of such hydroponic, felt-based, capillarity systems are implemented through closed-loop recycling to avoid unsustainable consumption (Séjalon-Delmas 2019). At Project-J for example, the high volumes supplied (15-30 in winter and 30-60 l m $\mathrm{m}^{-3}$ per day in summer) are mostly recirculated through a pond arrangement. It is significant to note that closed-loop systems do not necessarily ensure all unused water is recycled, as in practice $\sim 30$ $40 \%$ is estimated to be lost as wastage from spillage, blow-out onto adjoining areas, or other leakages (Turienzo 2018). Spillage and blow-out for example was observed at outdoor MV installations at Project-F and -H (Fig. 6); identified as a 'defect' at Project-A; and reported as a significant problem with several installations with considerable height (Turienzo 2018). It is significant to account for wastage as well as precipitation retention to prevent oversupply. While accounting for wastage is not straightforward, precipitation is accounted for in most outdoor installations by a rain sensor (e.g. Project-D). Although there is potential for employing precision irrigation strategies, none of the installations inspected were managing consumption to that degree of accuracy.

While oversupply must be prevented to ensure water-use efficiency, it is also necessary for plant health (Grant 2017). Hypoxic stress from waterlogging is reported as a challenge to identify given the external symptoms including reduced growth, chlorosis, leaf margin browning, root-rot, and wilting (Lamberts et al. 2008), could easily be misinterpreted as early signs of water stress and lead to an erroneous increase in supply. Examining system features could clarify oversupply, with high algal growth on the substrate and vicinity (e.g. as experienced at Project-A), and a high proportion of the irrigation supply accumulating as waste indicative of oversaturation.

\subsection{Nutrient supply}

External supply is necessary for living walls as the vertical growth substrate receives only a small fraction of the biomass litter. Nitrogen $(\mathrm{N})$, phosphorous $(\mathrm{P})$, and potassium $(\mathrm{K})$, along with essential trace-elements must therefore be supplied with concentrations varying across systems, seasonality, and plant profiles. In practice, most installations inspected maintained a constant supply (e.g. at the Project-J MV monthly usage is $\sim 1 \mathrm{~kg}$ of N:P:K at a 19:10:18 ratio), while a few reported a more bespoke approach. At Project-F for example, a varied N:P:K balance is used where at the start of the growth season in spring when growth is rapid (particularly with deciduous plants) a high $\mathrm{N}$ balance of 18:11:11 is used, while in autumn to 
prepare plant roots for cold stress, a 9:18:18 balance with low $\mathrm{N}$ and high $\mathrm{P}$ and $\mathrm{K}$ is used. For a given installation, the exact balance is advised to be adjusted with levels monitored regularly to maintain both appropriate concentrations and $\mathrm{pH}$. Excess concentrations were cautioned as it could alter salinity and substrate pH to disrupt necessary nutrient availability, or at worst lead to mineral toxicity associated failures (Turienzo 2018).

\subsection{Pollution stress}

Although the phytoremediation of pollutants is promoted as a vital ecosystem service, high concentrations were acknowledged as a significant stress source in outdoor conditions. The main offenders are particulate matter (PM), minerals, and inorganic gaseous pollutants such as Sulphur dioxide, Nitrogen oxides, and Ozone. Service-life contamination is unavoidable given that anthropogenic activity and deposition of pollutants are typically higher in urban environments, particularly adjacent to streets and construction sites (Weber et al. 2014). The outdoor installations inspected however have yet to report on critical stress incidents, with Project-E adjacent to a busy London street as the only project reporting minor issues. Save for plant replacement, experts highlighted few solutions to address pollution stress. Excessive deposition was suggested to be washed off, although this was cautioned given that closed-loop systems are likely to accumulate such pollutants that would in turn require intensive filtering.

\subsection{Microbiome management}

Management experts demonstrated general awareness of the significance of the plant microbiome in pollutant phytoremediation and nutrient recycling, with the greater significance of the rhizosphere microbiome acknowledged (see Weyens et al. 2015). Most however attached relevance of this aspect when considering indoor installations and specifically ALWs, while the only exception was reported with Project-H, where the expert acknowledged laboratory analyses to ensure substrate microbial balance as a regular maintenance task.

\subsection{Growth management}

Given the verticality, the risk of uprooting and fall-out from wind-induced canopy changes was stressed as a critical concern raised by installation owners. Maintenance pruning is therefore a necessary task, with the outdoor installations inspected yet to report a major fall-out incident. The high planting densities also mean that certain canopies must be trimmed to prevent overshadowing from crown domination. Project-B for example had reported crown domination as a contributing factor for the poor health of adjacent lower-level plants. Other growth management tasks mentioned included training (e.g. for climbing plants), realignment, and in certain instances replanting when dislodged from excessive root growth (pushback). Pushback was reported as a typical concern with indoor installations where optimal growth conditions are maintained throughout the year (Séjalon-Delmas 2019; Ward 2018a). Project- 
B and -J as examples, reported root growth out of the root zone, and in the latter case, fallout. The experts suggested indoor installations as typically requiring a higher frequency of growth management tasks, which is reflected in their annual maintenance cost (e.g. $6 \%$ at Project-C relative to $12.5 \%$ at Project-B, both managed by the same consultant).

\subsection{Biotic stress management}

Synthetic ecosystems attract biotic stress from colonising species of flora, fauna, and pathogens as an abundance of resources are made available for enhancing biodiversity with little to no control mechanisms. This vulnerability was reported to be greater with indoor installations, where controlled microclimates present near constant favourable conditions (Turienzo 2018; Ward 2018a). A degree of installation resilience is provided by their planting density and diversity, as pests and diseases are often species-specific. Installation managers however are likely to deploy immediate remedial measures following threat detection. These may include the use of pesticides, herbicides, or antipathogens, although these are cautioned given the potential for unintended consequences. As an ecologically sound alternative, the introduction and maintenance of natural control mechanisms was strongly advocated by most experts (Turienzo 2018; Ward 2018a).
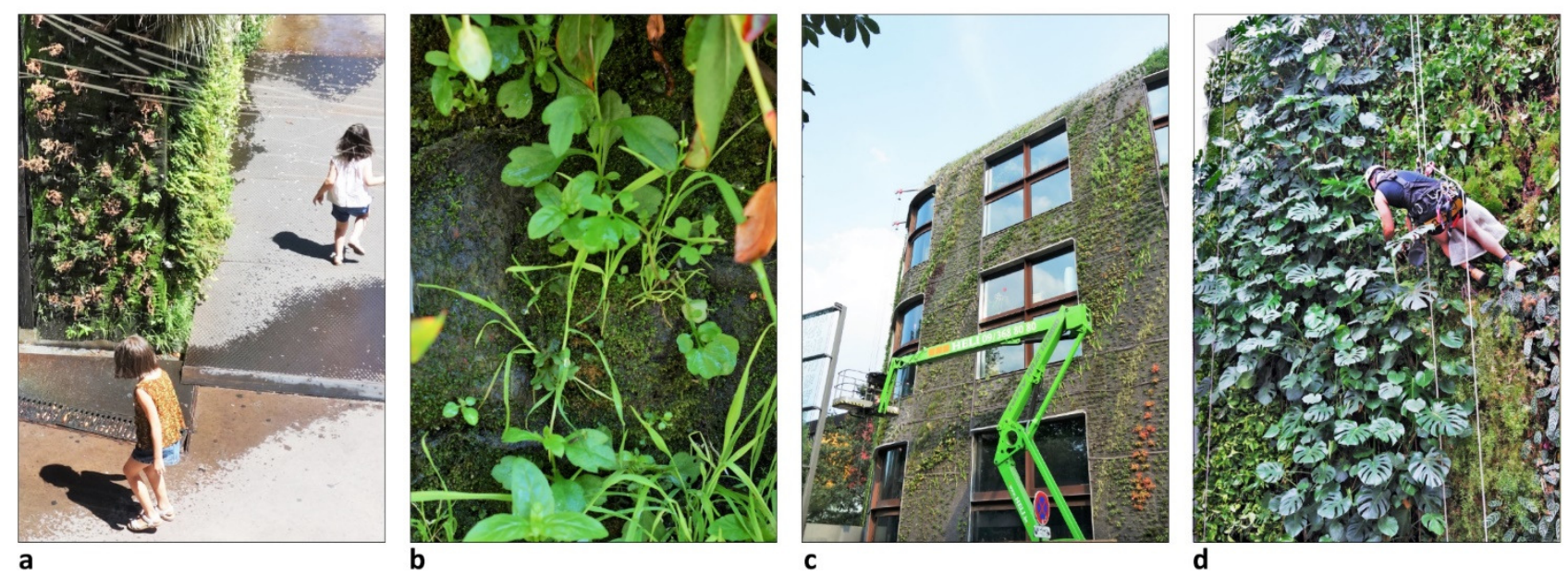

Fig. 6. Watering wastage (a); weeds taken root (b); replanting with articulated lift (c); canopy trimming by an abseiler (d).

Although verticality has been claimed to limit weed propagation (e.g. Blanc, 2012), installation inspections demonstrated it to present a recurring maintenance problem (e.g. Project-F, Fig. 6b). Most experts advocated preference for addressing weeds as well as pests and diseases with biological control, where the mechanisms of predation, parasitism, or herbivory of other organisms is utilised (McEvoy 2019; Ward 2018a). As an alternative, mild threats may be managed with biopesticides, while the use of stronger synthetic pesticides was cautioned in indoor 
spaces given the potential to adversely affect building occupant health. Synthetic pesticide use is also a problem with closed-loop irrigation systems, as they accumulate in wastewater leading to toxicity stress risk that is challenging to filter-out (Ward 2018a).

Human physical contact is also a source of plant biotic stress. Excessive handling of foliage and vandalism are significant concerns typically highlighted in design guidance, particularly with publicly accessible arrangements (e.g. Project-E, -F, and -H). With the inspected installations however, the managers reported the threat from accidental damage or vandalism to be less than assumed. Most human physical interactions with plants have been reported as noninjurious (Turienzo 2018); an observation reinforced by the behavioural engagement studies carried out.

\subsection{Infrastructure maintenance}

Irrigation and fertigation are typically implemented as an integrated delivery system and involves a range of tasks including the maintenance of flow networks and active apparatus; accumulated waste disposal; filtering; and frost protection (Bonnin 2017; Turienzo 2018). In contrast to modular systems, embedded networks in continuous arrangements are reported to be onerous to maintain given the difficulty in detecting and remedying leaks, blockages, or invasive root growth into pipework (Grant 2017). Hydroponic arrangements (e.g. MV), consider the substrate as an integrated aspect of the delivery system, with monitoring of felt degradation as an additional task (Bonnin 2017). At a certain point however, significant felt replacement and replanting is reported as necessary (e.g. Project-F and -H), which is a significant drawback and maintenance cost of such systems (Turienzo 2018).

All maintenance tasks require infrastructure and apparatus to be used, with some requiring permanent support features, while others are introduced per site visit (Grant 2017; Turienzo 2018). Access particularly at larger installations is a key consideration that installation designers must address, with some requiring the use of cranes and gantries with substantial access and loading burdens, or inbuilt infrastructure necessary for climbers or abseilers (Fig. 6). When such considerations have not been adequately addressed during the design stage, onerous alternatives may need to be considered during the installation service-life, which inevitably increases maintenance costs.

Notably, at most installations a significant proportion of tasks are still reported to be managed manually requiring the physical presence of the installation manager. Remote management apparatus at present is only reported to be used for irrigation flow control, with several experts utilising mobile applications to monitor conditions through embedded sensors and valves operated to complement. Real-time stress detection and automated response mechanisms were not in operation at any of the installations inspected, despite the significant prominence and resource availability at some installations. 


\section{Conclusion}

Installation managers highlight atypical extremes of abiotic stressors including water, temperature, and light as the most challenging to address with outdoor urban installations; particularly during the construction phase and the initial establishing period; and when local climate variability has been underestimated. The challenge is highlighted by the rapid escalation of adverse effects; as experienced at the failed project reported in this study. With indoor installations, vulnerability to such extremes is significantly limited by the near closed nature of the local climate. Instead, optimal growth conditions maintained throughout the year often translate to higher growth management requirements.

The sustained success of an installation depends on resource consumption and the diligent and consistent management of the maintenance programme. At any installation, the failure of a proportion of plants would be explained by the challenges presented by plant stressors and the ability of the plants to self-manage the resulting consequences, as well as by the management and maintenance team's ability to respond with necessary interventions when such efforts are failing. In contrast, the complete failure of installations is more likely to stem from fundamental design flaws or substantial management and maintenance team failures to maintain plant stress management infrastructure. It is significant to note that the management tasks inspected seemed to be dependent on the monitoring diligence and competence of the managers, with none employing smart sensor data-driven technologies to automate processes. The adoption of such technologies in the future is likely to offer the opportunity to reduce existing maintenance burdens and resource consumption.

The methodologies employed by the respective managers highlighted varying complexity, with a few bespoke to the installation profile. In terms of resource consumption, soil-based systems were expressed to offer significant water-use and material replacement advantage, along with higher planting densities and flexibility. The popular hydroponic felt-based systems in contrast were expressed to present higher water-use and material replacement burdens in agreement with previous studies (e.g. Perini et al., 2013; Perini and Rosasco, 2013). The latter however offered the highest planting diversity (order of magnitude greater) to present visually flourishing installations, which suggested association with the increased frequency of human engagement behaviour observed. Sustaining flourishing installations could be said to be influenced by the ability to sustain human engagement interest, with the interaction from public and building occupants highlighted as a key motivator by installation managers. This hypothesis however needs to be investigated further in future research, as the limited sample size and number of site visits in this study limits significant correlations from being identified. Further observational study is therefore encouraged including failed projects, while the limited number of failed projects in the European context at present could be considered as an indicator of the general commitment of installation managers toward sustaining thriving ecosystems. 


\section{Acknowledgment}

The work described in this paper is part of a doctoral studentship funded by the UK Engineering and Physical Sciences Research Council.

\section{Appendix}

Table A1. Summary of incidents and issues reported in interviews and recorded at site inspections (SI).

\begin{tabular}{|c|c|c|}
\hline Case study & Plant health & General maintenance \\
\hline Project-A & $\begin{array}{l}\text { Plants had suffered high wind exposure as it is in a } \\
\text { remote location with no contextual buildings. } \\
\text { Cold stress in winter, and frost damage mitigation } \\
\text { had led to dry-out. } \\
\text { SI: entire installation removed in } 2015 \text {. }\end{array}$ & $\begin{array}{l}\text { Water and nutrient blown-out (high wastage) to } \\
\text { present a slip-hazard in summer and ice risk in } \\
\text { winter. } \\
\text { Water wastage had encouraged algae growth on } \\
\text { paving and façade. } \\
\text { Water ingress from the envelope was a major } \\
\text { defect. }\end{array}$ \\
\hline Project-B & $\begin{array}{l}\text { The atrium has four ground-level entrance heaters, } \\
\text { which during the first winter had caused localised } \\
\text { heat stress. } \\
\text { Maranta leuconeura affected by entrance heaters, } \\
\text { crown shading from neighbouring Monstera } \\
\text { deliciosa, and a spider mite infestation. } \\
\text { SI: above replaced and M. deliciosa. trimmed in } \\
\text { June } 2018 \text {. }\end{array}$ & Irrigation leakages reported and repaired. \\
\hline Project-C & $\begin{array}{l}\text { Helleborus sp. had suffered aphid attack, but } \\
\text { successfully treated. } \\
\text { SI: plants in shaded wall corners in poor health. }\end{array}$ & Typical issues with weed presence and trimming. \\
\hline Project-D & $\begin{array}{l}\text { Seasonal flowering plants used to satisfy client } \\
\text { aesthetic requirements. } \\
\text { SI: sporadic plant failures, although few }(<5 \%) \text { and } \\
\text { far apart. }\end{array}$ & $\begin{array}{l}\text { Increased soil depth }(\sim 200 \mathrm{~mm}) \text { allows for rapid } \\
\text { growth, which demands regular trimming. } \\
\text { Rainwater harvester and rainfall monitoring are } \\
\text { added maintenance tasks. } \\
\text { SI: inspections and works require a gantry to be } \\
\text { installed. }\end{array}$ \\
\hline Project-E & $\begin{array}{l}\text { Initial plant-plan modified over first few years to } \\
\text { adapt to local constraints; e.g. some had failed } \\
\text { under pollution stress. Seasonal plants are also } \\
\text { used. } \\
\text { SI: crown domination from certain plants, with } \\
\text { some detrimental impact on those overshadowed; } \\
\text { and dead plants at corner apex, possibly from } \\
\text { wind stress. }\end{array}$ & $\begin{array}{l}\text { Challenge to balance watering requirements given } \\
\text { the installation height. } \\
\text { SI: Several window openings were overshadowed by } \\
\text { excessive growth and required trimming. }\end{array}$ \\
\hline Project-F & $\begin{array}{l}\text { Initial plant-plan modified to adapt to south-facing } \\
\text { exposure. Some evergreen shade-loving plants had } \\
\text { struggled to flourish. } \\
\text { SI: Hosta patriot exhibited leaf edge browning; } \\
\text { some new additions to the wall-edge returns had }\end{array}$ & $\begin{array}{l}\text { Major plant failures }(\sim 90 \%) \text { during construction in } \\
\text { summer caused by accidental water cut-off. } \\
\text { Major refurbishment including full replanting } \sim \text { four } \\
\text { years ago, owing to felt deterioration and invasive } \\
\text { root growth into pipework. }\end{array}$ \\
\hline
\end{tabular}




\begin{tabular}{|c|c|c|}
\hline Case study & Plant health & General maintenance \\
\hline & $\begin{array}{l}\text { failed to take root; and at the apex, some plants } \\
\text { exhibited wind stress symptoms. }\end{array}$ & $\begin{array}{l}\text { Higher water volume delivered to the first few } \\
\text { drippers in contrast to peripheries; initial nine } \\
\text { sectors extended to eleven to address. The } \\
\text { problem was acute enough that for a period } \\
\text { sedum plants were introduced. } \\
\text { Weeds are a major problem and grow rapidly; takes } \\
\text { 2-4 days to de-weed. No pests, possibly due to } \\
\text { aversion to higher irradiation from south-facing } \\
\text { aspect. }\end{array}$ \\
\hline Project-G & $\begin{array}{l}\text { SI: mild wind stress noted at the apex; and crown } \\
\text { domination from certain plants, although no } \\
\text { adverse consequences noted. }\end{array}$ & $\begin{array}{l}\text { SI: the gable-end wall had several window openings } \\
\text { overshadowed by excessive growth and required } \\
\text { trimming. }\end{array}$ \\
\hline Project-H & $\begin{array}{l}\text { Higher frequency of detailed inspections (six per } \\
\text { year) to address horticultural needs and plant } \\
\text { replacement. } \\
\text { SI: installation was undergoing replanting, with half } \\
\text { the wall completed and young plants taking root. }\end{array}$ & $\begin{array}{l}\text { Significant trimming in } 2007 \text { to mitigate fall-off risk. } \\
\text { Major refurbishment, including full replanting } \\
\text { undertaken between } 2017-18 \text {. } \\
\text { Laboratory analysis of felt routinely carried out. } \\
\text { SI: irrigation sessions showed significant supply } \\
\text { draining into the waste collection channel at base. }\end{array}$ \\
\hline Project-I & $\begin{array}{l}\text { Some plants (e.g. M. deliciosa) exhibited aggressive } \\
\text { growth in the well-lit indoor atrium. } \\
\text { SI: few plants exhibited leaf-edge browning. }\end{array}$ & $\begin{array}{l}\text { Plants regularly trimmed to limit growth. } \\
\text { Drainage tray at the bottom requires regular } \\
\text { clearing out, as its contents are visible. } \\
\text { SI: installation artificially lit even during the day. }\end{array}$ \\
\hline Project-J & $\begin{array}{l}\text { Orchidaceae and Bromeliaceae had failed due to } \\
\text { insufficient light. } \\
\text { Plant pushback and fall-out (e.g. Philodendron sp.) } \\
\text { from excessive weight. } \\
\text { Some plants (e.g. Drynaria sp., Kohleria sp., and } \\
\text { Ficus sp.) frequently trimmed. } \\
\text { SI: high levels of algae growth. }\end{array}$ & $\begin{array}{l}\text { Original } 1996 \text { installation dismantled for major } \\
\text { renovation. } \\
\text { Occasional failures with automated water and } \\
\text { humidity control apparatus ( } \mathrm{RH} \text { kept at } 80 \% \text { ). } \\
\text { SI: significant supply drains into base-pond (not an } \\
\text { aquaponic arrangement). }\end{array}$ \\
\hline
\end{tabular}

\section{References}

Blanc, P. (2012). The Vertical Garden: From Nature to the City. (V. Lalot, Ed.), Revised Ed, New York: W.W. Norton.

Bonnin, J. (2017). Deputy Director of Technical Resources. Personal communication. 29 November, Paris.

Bryman, A. (2016). Social research methods, 5th edn, Oxford: Oxford University Press.

Collins, R., Schaafsma, M., \& Hudson, M. D. (2017). The value of green walls to urban biodiversity. Land Use Policy, 64, 114-123.

David, J., \& RHS. (2013). A New System of Plant Hardiness Ratings for the British Isles. The Plantsman, 138, 68-69.

Grant, G. (2017). Ecologist and living wall consultant. Interviewed by Gunawardena, K. 15 November, London.

Gunawardena, K. R., \& Kershaw, T. (2016). Green and blue-space significance to urban heat island mitigation. In S. Emmit \& K. Adeyeye, eds., Integrated Design International Conference (ID@50), Bath: University of Bath, p. 15 . 
Gunawardena, K. R., Wells, M. J., \& Kershaw, T. (2017). Utilising green and bluespace to mitigate urban heat island intensity. Science of the Total Environment, 584-585, 1040-1055.

Gunawardena, K., \& Steemers, K. (2019a). Living wall influence on microclimates: an indoor case study. In CISBAT 2019 Special Issue of Journal of Physics: Conference Series, IOP Science.

Gunawardena, K., \& Steemers, K. (2019b). Living walls in indoor environments. Building and Environment, 148(November 2018), 478-487.

Lamberts, H., Stuart Chapin, F., Pons, T. L., ... Pons, T. L. (2008). Plant Physiological Ecology, Second, Springer New York.

McEvoy, N. (2019). Living wall consultant. Personal communication. 11 March.

Monteith, J., \& Unsworth, M. (2013). Principles of environmental physics, 4th edn, Oxford: Academic Press, an imprint of Elsevier.

Perini, K., Ottelé, M., Haas, E. M., \& Raiteri, R. (2013). Vertical greening systems, a process tree for green façades and living walls. Urban Ecosystems, 16(2), 265-277.

Perini, K., \& Rosasco, P. (2013). Cost-benefit analysis for green façades and living wall systems. Building and Environment, 70, 110-121.

Séjalon-Delmas, N. (2019). Senior Lecturer at Université Toulouse III - Paul Sabatier. Personal communication. 21 February.

Turienzo, J. L. (2018). Agricultural Engineer and living wall consultant. Interviewed by Gunawardena, K. 09 August, Madrid.

Ward, T. (2018a). Living wall consultant. Interviewed by Gunawardena, K. 22 January, Cambridge.

Ward, T. (2018b). Living wall consultant. Personal communication. 13 December.

Weber, F., Kowarik, I., \& Säumel, I. (2014). Herbaceous plants as filters: Immobilization of particulates along urban street corridors. Environmental Pollution, 186, 234-240.

Weyens, N., Thijs, S., Popek, R.,... Gawronski, S. W. (2015). The role of plant-microbe interactions and their exploitation for phytoremediation of air pollutants. International Journal of Molecular Sciences, 16(10), $25576-25604$. 